American Journal of Pharmaceutical Education 2018; 82 (8) Article 6345.

\title{
RESEARCH
}

\section{An Effective Approach to Teaching Pharmacogenomics in the First Year of Pharmacy Curriculum}

\author{
Marina Gálvez-Peralta, PharmD, PhD, Grazyna D. Szklarz, PhD, Werner J. Geldenhuys, PhD, BPharm, \\ Paul R. Lockman, PhD, BSN \\ School of Pharmacy, West Virginia University, Morgantown, West Virginia \\ Submitted February 16, 2017; accepted October 25, 2017; published October 2018.
}

Objective. To develop an effective method in teaching pharmacogenomics as a part of a new course, Biopharmaceutics and Pharmacogenomics.

Methods. Teaching effectiveness was measured by quizzes, retrospective pre- and post-surveys, team activities, and journal reflections. Four team activities were included in the course: genomic disease, patient case, genetic counselor and a debate about personalized medicine. Outcomes and course impact were evaluated at the end of the course. The evaluation methods included the assessment of knowledge, students' perceptions regarding the utility of team activities, the impact of the course on students' confidence to discuss pharmacogenomics with health care providers or patients, and long-term knowledge retention, measured in the following P2 semester.

Results. Seventy-six students were enrolled in the course. Multiple assessments during the course demonstrated that students' knowledge of pharmacogenomics improved. The team activities had a positive impact on student learning, and the course improved their confidence level to discuss pharmacogenomics with another health care provider or a patient. While $86 \%$ of the students considered themselves "unconfident," "somewhat unconfident" or "neither confident nor unconfident" at the beginning of the course, 91\% reported being "confident" or "somewhat confident" by the end of the course. This increase in confidence was statistically significant. Furthermore, students showed knowledge retention six months after taking the course.

Conclusion. Implementation of a new course in pharmacogenomics was effective and well received by the students. It also prepared students for system-based therapeutics courses later in the curriculum.

Keywords: pharmacogenomics, pharmacogenetics, critical thinking, concepts integration, new course

\section{INTRODUCTION}

Although the idea of individualized response to treatments was observed by Lucretius in $50 \mathrm{BC}$ defending that "What is food to one man, is bitter poison to others," it wasn't until 1950 when the concepts of "pharmacogenetics" and "pharmacogenomics" were introduced. ${ }^{1}$ With the new Accreditation Council for Pharmacy Education (ACPE) Standards, pharmacy students should be prepared to understand and apply pharmacogenomics concepts to patient care. ${ }^{2}$

The National Human Genome Research Institute (NHGRI) of the National Institutes of Health identified five core competencies with respect to pharmacogenomic educational needs for pharmacists: terminology, knowledge,

Corresponding Author: Marina Gálvez-Peralta, Department of Pharmaceutical Sciences, School of Pharmacy, 1 Medical Center Dr., West Virginia University, Morgantown, WV 26506. Tel: 304-293-1480. E-mail: magalvezperalta@hsc. wvu.edu interpretation, communication, and professionalism..$^{3,4}$ These core competencies have been endorsed by major health organizations, including the National Coalition for Health Professional Education in Genetics (NCHPEG), ${ }^{4}$ the International Society of Pharmacogenomics, ${ }^{5}$ the Accreditation Council for Pharmacy Education (ACPE), ${ }^{2}$ American College of Clinical Pharmacy (ACCP) ${ }^{7}$ the American College of Clinical Pharmacy (ACCP) Educational Affairs Committee, the American Society of Health-System Pharmacists (ASHP) ${ }^{8}$ and the NIHfunded Genetic/Genomics Competency Center (G2C2). ${ }^{2}$ Following these recommendations, multiple approaches describing the incorporation of pharmacogenomics in the education of health care providers have been published. ${ }^{9-11} \mathrm{~A}$ pharmacist's responsibilities are to educate patients about pharmacogenomic principles and to advocate the rational and routine use of pharmacogenomic testing when indicated. ${ }^{8}$

These recommendations can be assisted by the advances in new technologies and direct-to-consumer testing offered by many companies. However, social media 


\section{American Journal of Pharmaceutical Education 2018; 82 (8) Article 6345.}

convey the somewhat overly optimistic promises that all diseases will become treatable after the completion of the genomic project. ${ }^{12}$ Therefore, pharmacists must become leaders and key professionals who provide valid information about pharmacogenomics to patients and other health care providers.

These scientific and social factors were considered when the new course, "Biopharmaceutics and Pharmacogenomics," was designed. That is why several group activities were included, with the objective of enhancing students' critical thinking and knowledge. This course is offered during the spring semester of the first year (P1) of the 4-year PharmD professional program at the School of Pharmacy at West Virginia University. At WVU, students are accepted after a minimum of two years of prepharmacy education.

The PharmD program at the WVU School of Pharmacy underwent a curricular change in 2015 with the integration of basic and clinical sciences within courses. While in the traditional curriculum, pharmacogenomics was taught in the P3 fall course as part of the course "Pharmacokinetics and Pharmacogenomics," in the new curriculum, pharmacogenomics was moved to the P1 spring semester. The ultimate goals of this change were two-fold: first, to provide a basis to understand and to interpret pharmacogenomics information and, second, to be able to apply pharmacogenetic principles in future system-based therapeutic courses offered during P2 and P3 years. With this new model, students would have already acquired a foundation in pharmacokinetics, biopharmaceutics, biotechnology, and biochemical pharmacology prior to or during the same semester that the pharmacogenomics module was offered. The pharmacogenomics section of the course was designed with formal lectures, class discussions, homework assignments, journal reflections, and team activities that included, among others, a debate about personalized medicine and a genetic counselor guest speaker (further details in the method section). The authors of this study hypothesized that the introduction of pharmacogenomics early in the students' curriculum and the use of these specific active learning activities would set the foundations to apply pharmacogenetics concepts in their pharmacy practice.

\section{METHODS}

The Biopharmaceutics and Pharmacogenomics course was first implemented in the spring of 2016 as a four-credit course. One hour per week was dedicated for a team activity or a quiz, while the other three sessions were for lectures. The sessions that discussed pharmacogenomics were offered in the second half of the semester, with a total of 29 sessions, and conducted mostly by one instructor. Sessions were divided between lecture time and team activities. The focus of the latter was to enhance the learning and applicability of pharmacogenomics to pharmacy practice.

Student learning was assessed with quizzes, retrospective pre- and post-surveys, team activities, and journal reflections (this last one was not graded and voluntary). Outcomes and course impact were measured from a survey at the end of the course.

Four team activities were offered in the pharmacogenomics section of the course. A summary of their description with the objectives and NHGRI and Center for the Advancement of Pharmacy Education (CAPE) competencies are summarized in Table 1.

The first activity required each team to write a fourpage long paper describing a Mendelian disease of their choice, type of inheritance, variations that could cause disease severity, frequency of distribution among different ethnicities or races, changes in the diagnosis and treatment of the disease (traditional vs genomic era), and the role of the pharmacist in helping patients understand the disease. The objective of this activity was to familiarize students with different databases, pedigrees, and genetic terminology. This activity covered terminology, knowledge, interpretation, and professionalism as the core genomic educational needs recommended by the NHGRI and pharmacists organizations. ${ }^{3}$ The paper was evaluated for content and professionalism in its format. The following resources were suggested to students as an aid for the assignment: Genetics Home Reference, Genes and Disease, Medline Plus, Genetic Testing Registry, Single Nucleotide Polymorphism, and Clinical Trials.gov.

The second activity was a short verbal presentation on a drug of their choice addressing the gene and variant allele affected, penetrance and expressivity, phenotype, pharmacokinetic and/or pharmacodynamics consequences, therapeutic recommendations such as dose adjustment, change of medication, need for screening prior to prescribing the therapy, recommendation for monitoring drug levels, and level of evidence indicated by the Clinical Pharmacogenetics Implementation Consortium (CPIC), using PharmGKB and FDA package insert recommendations. The learning objectives for this activity were to familiarize students with the PharmGKB website, identify levels of evidence, determine when dosing guidelines or other recommendations are being approved, and counsel for specific drugs linked to genotypes. This activity would train students in pharmacogenetics/pharmacogenomics terminology, knowledge, interpretation, communication, and professionalism ${ }^{3}$ for their future careers in pharmacy.

The third activity consisted of a genetic counseling session that included obtaining a firsthand input from 
American Journal of Pharmaceutical Education 2018; 82 (8) Article 6345.

Table 1. Comparison of Activities, Objectives, Educational Genomic Core Need Addressed, and Educational Outcomes (CAPE)

\begin{tabular}{|c|c|c|c|c|}
\hline $\begin{array}{l}\text { Team } \\
\text { Activity } \\
\#\end{array}$ & Type of Activity & Objectives & $\begin{array}{c}\text { Educational } \\
\text { Genomic Core } \\
\text { Need Addressed } \\
\end{array}$ & $\begin{array}{c}\text { Educational Outcomes } \\
\text { (CAPE) }\end{array}$ \\
\hline$\overline{1}$ & $\begin{array}{l}\text { Paper exploring } \\
\text { Mendelian Disease }\end{array}$ & $\begin{array}{l}\text { Familiarization with databases, } \\
\text { pedigrees and genetic } \\
\text { terminology. }\end{array}$ & $\begin{array}{l}\text { Terminology } \\
\text { Knowledge } \\
\text { Interpretation } \\
\text { Professionalism }\end{array}$ & Knowledge (1) \\
\hline 2 & $\begin{array}{c}\text { Verbal presentation on } \\
\text { pharmacogenomics }\end{array}$ & $\begin{array}{l}\text { Familiarization with PharmGKB, } \\
\text { levels of evidence, dosing } \\
\text { guidelines/recommendations } \\
\text { and counseling. }\end{array}$ & $\begin{array}{l}\text { Terminology } \\
\text { Knowledge } \\
\text { Interpretation } \\
\text { Communication } \\
\text { Professionalism }\end{array}$ & $\begin{array}{l}\text { Knowledge (1), Improving } \\
\text { communication (3), } \\
\text { Empathy and } \\
\text { self-awareness (4) }\end{array}$ \\
\hline 3 & Genetic counseling & Role playing & $\begin{array}{l}\text { Knowledge } \\
\text { Interpretation } \\
\text { Communication } \\
\text { Professionalism }\end{array}$ & $\begin{array}{l}\text { Knowledge (1), Improving } \\
\text { communication (3), } \\
\text { Self-awareness (4) }\end{array}$ \\
\hline 4 & $\begin{array}{l}\text { Class debate about } \\
\text { personalized medicine } \\
\text { and genetic } \\
\text { sequencing }\end{array}$ & $\begin{array}{l}\text { Comparison of information posted } \\
\text { on social media with scientific } \\
\text { data. Ethics, law and regulations } \\
\text { of genetic information. Prepare } \\
\text { students to answer real patients' } \\
\text { questions and information } \\
\text { posted on social media. }\end{array}$ & $\begin{array}{l}\text { Terminology } \\
\text { Knowledge } \\
\text { Interpretation } \\
\text { Communication } \\
\text { Professionalism }\end{array}$ & $\begin{array}{l}\text { Knowledge (1), Improving } \\
\text { communication (3), } \\
\text { Cultural sensitivity (3), } \\
\text { Empathy and } \\
\text { self-awareness (4) }\end{array}$ \\
\hline
\end{tabular}

a genetic counselor about genotoxicity and a role-play session. In the latter session, students role-played as pharmacists and enacted how they would counsel if they had the Mendelian disease that they worked on during the first assignment, or if the patient is taking the medication that was investigated in the second assignment.

The fourth activity was a class debate on personalized medicine. This activity took place after the lectures on legal and ethical components of pharmacogenomics. The debate was divided in two sessions on consecutive days. At the beginning of the pharmacogenomic sessions, teams were randomly assigned to be "for" or "against" personalized medicine and given enough time to compile and contrast information by the end of the semester. During the first session, the team leaders justified the reasoning behind their assigned point of view. During the second session, the instructor (debate facilitator) brought up the most common topics mentioned by the team leaders, and they were discussed by all the students. In addition, students completed a survey to measure their personal inclination toward the topic before, during, and after the debate to obtain their perceptions about personalized medicine and genetic sequencing. The learning objective for this activity was to prepare student pharmacists to face real patients' questions, concerns, and information posted in social media, with the ultimate goal of educating patients, and to become an advocate for the rational and routine use of pharmacogenomic testing in appropriate circumstances. $^{3,8}$

Students were asked to sign up for a 6-8 member team with classmates of their choice. These teams were maintained throughout the entire pharmacogenomics section of the course. Team members chose a leader for each group activity. The aim of including a leader was to enhance student professionalism and leadership skills. Students peer-reviewed by providing feedback on accountability, participation, communication, responsibility, identification of skills, and cooperation. This feedback was shared anonymously with individual students for personal development.

A voluntary and anonymous survey was offered to students at the end of the course to evaluate the utility of having group learning activities and the potential benefits of the individual team activities. In addition to the team activities, students were engaged in other activities during lecture times, such as real-time audience questions using the SOLE (Study Observe Learn Engage West Virginia University Health Science portal) surveys to monitor and assess in real-time their understanding of the topic 


\section{American Journal of Pharmaceutical Education 2018; 82 (8) Article 6345.}

discussed that day as well as clinical cases prior to the introduction of some concepts.

The course impact on student confidence in pharmacogenomics was measured by asking them anonymously for their perception regarding the level of confidence in pharmacogenomics counseling or discussing this topic with other health care providers. The retrospective survey included questions measuring student confidence before and after taking the course, with both types of questions given at the end of the course. This allowed the study authors to compare anonymously retrospective pre- and post-answers for individual students, and to ensure an identical level of participation. The results of the preand post-retrospective survey were evaluated with Chisquare test using Prism 5.0 (GraphPad Software Inc., La Jolla, CA). This study was approved by West Virginia University Institutional Review Board as exempt.

Long-term knowledge retention was tested 6 months after the pharmacogenomics course was finalized, during P2 fall semester in System Based Therapeutic Courses (SBT), without early notice to students. Several nongraded questions were part of one of the sessions, and the responses helped the instructor to assess the level of students' pharmacogenomics knowledge retention and understanding prior to introducing specific clinical scenarios. The questions referred to basic concepts or drugs mentioned in the P1 Biopharmaceutics and Pharmacogenomics course and were answered anonymously with no grade associated to it. In addition, new pharmacogenomics questions were asked in some examinations in systembased therapeutic courses. These questions involved more complex concepts, clinical scenarios and exceptions, and were used to assess the utility of introducing a pharmacogenomics module in the first year, as well as the retention of basic concepts.

\section{RESULTS}

Seventy-six students were enrolled in the Biopharmaceutics and Pharmacogenomics course during 2016. Quizzes and a final examination were scheduled in the course to assess their learning of the pharmacogenomics material. Table 2 contains the percentage of questions answered correctly for each category of questions based on Bloom's taxonomy for the pharmacogenomics section of the course. Most of the students ( $80 \%$ to $85 \%)$ were able to satisfactorily answer high-level rated questions. All students passed the course with 50 receiving a grade of A and 26 receiving a $\mathrm{B}$.

Students had the opportunity to provide feedback anonymously on the learning and utility of the four team activities offered in the pharmacogenomic section of the course (Table 3). Seventy-three out of the 76 students in
Table 2. Percentage of Questions Answered Correctly Based on Bloom's Level in Different Quizzes and Final Examination

\begin{tabular}{lcc}
\hline Bloom's Level & $\begin{array}{c}\text { Number of } \\
\text { Questions }\end{array}$ & $\begin{array}{c}\text { \% of Questions Answered } \\
\text { Correctly, Mean (SD) }\end{array}$ \\
\hline Knowledge & 19 & $91(8)$ \\
Comprehension & 72 & $89(10)$ \\
Analysis & 40 & $80(11)$ \\
Application & 45 & $83(14)$ \\
Synthesize/ & 71 & $85(8)$ \\
$\quad$ Evaluate/Create & & \\
\hline
\end{tabular}

the class answered the questionnaire. Ninety-two percent of the students who answered the questionnaire found the incorporation of active learning activities to be very useful or somewhat useful, and would recommend the activities to other students. Moreover, $95 \%$ of students agreed or strongly agreed that the activities helped them to acquire new knowledge, while 4\% were neutral, and 92\% were satisfied with those activities. In addition, $92 \%$ of students agreed or strongly agreed that the learning environment was conductive.

The activity considered to be the most useful (very useful or somewhat useful) by $94 \%$ of students was the pharmacogenomics patient case exploring a particular treatment through PharmGKB, identifying key points to counsel patients and to discuss the pharmacogenomics of the treatment with health care providers (Table 3 ).

Students also shared their perception about genetic testing and personalized medicine $(\mathrm{N}=61$ out of 76$)$ from the Team Activity 4 (Debate). To assess how the debate influenced their opinions on personalized medicine, three questions were asked about their position prior to the random assignment to the "for" or "against" groups; their position during the debate; and their position after it. A flowchart showing the change in their positions is depicted in Figures 1A and 1B. It is noteworthy to observe the evolution of the 20 undecided students before and after the activity. By the end of the debate, the personal position of nine of these students seemed to be influenced by the team to which they were randomly assigned ("for" or "against"). However, seven students who initially were undecided and assigned to the "against" teams, were still undecided by the end of the debate. Six students who had a personal position at the beginning of the activity changed to undecided by the end of the experience. Students acknowledged the fact that the points of view during the debate were assigned, and not their own.

It is noteworthy to mention some of the students' opinions about the personalized medicine from the debate. Despite their awareness of the Genetic Information Nondiscrimination Act (GINA), some students in the 


\section{American Journal of Pharmaceutical Education 2018; 82 (8) Article 6345.}

Table 3. Student Perception on Active Learning Activities During the Pharmacogenomics Section of the Course ( $N=73$ out of 77 students)

\begin{tabular}{|c|c|c|c|c|c|c|}
\hline & \multicolumn{6}{|c|}{ Participant Response, No. (\%) } \\
\hline & VU & SU & $\mathbf{N}$ & NU & DK & $\mathbf{N A}$ \\
\hline $\begin{array}{l}\text { Do you consider the incorporation of the former active learning activities useful } \\
\text { for your career development and practice as PharmD? }\end{array}$ & $40(55)$ & $27(37)$ & $1(1)$ & $1(1)$ & $2(3)$ & $1(1)$ \\
\hline $\begin{array}{l}\text { How did each of the following team activities help you to better understand } \\
\text { pharmacogenomics and which one would you consider to be more useful in } \\
\text { your future as a pharmacist? }\end{array}$ & & & & & & \\
\hline 1: Bioinformatics & $28(38)$ & $31(42)$ & $9(12)$ & 0 & $4(5)$ & $1(1)$ \\
\hline 2: Personal case on pharmacokinetics-pharmacodynamics and pharmacogenomics & $40(55)$ & $29(39)$ & $2(3)$ & 0 & $1(1)$ & $1(1)$ \\
\hline 3: Genetic counseling & $33(45)$ & $22(30)$ & $15(20)$ & $1(1)$ & & $1(1)$ \\
\hline 4: Personalized medicine and genetic sequencing debate & $26(36)$ & $29(40)$ & $12(16)$ & $1(1)$ & $3(4)$ & $1(1)$ \\
\hline
\end{tabular}

Abbreviations: VU= very useful, $\mathrm{SU}=$ somewhat useful, $\mathrm{N}=$ neither useful nor useless, $\mathrm{NU}=$ not useful, $\mathrm{DK}=$ don't know if this activity would be useful for my future as pharmacist, NA=not answered (students answered other questions but left this section blank)

"against" team were concerned about negative consequences of knowing their own genetic information, such as psychological impact on themselves and on their families after discovering that they could be at risk of potentially developing a disease, or having a mutation that was correlated with no cure or poor prognosis, and the lifetime implications.

The debate about personalized medicine brought several benefits without the need of facing the risks related to students' genetic sequencing. These benefits include: students prepared themselves according to different scenarios and other ways of thinking, empathizing and drawing conclusions; students felt the environment was safe, since they were not sharing their own point of view, but what was randomly assigned; standards 1 , 3 and 4 (knowledge, improving communication, cultural sensitivity, empathy and self-awareness) of Center for the Advancement of Pharmacy Education (CAPE) ${ }^{6}$ were addressed. The purpose of this fourth team activity was to help students be better prepared for potential questions from patients, ${ }^{13}$ such as the interpretation and meaning of genetic testing ${ }^{14}$, direct to consumer testing, or patients' expectations regarding scientific information. Daly reported that all of these proposals should be part of the pharmacist training. ${ }^{15}$

At the end of the course, 73 students completed a survey assessing their confidence level in discussing pharmacogenomics concepts with health care providers and patients in comparison to the confidence level that they had at the beginning of the course (Figure 2). At the beginning of the course, $86 \%$ of students considered themselves as "unconfident," "somewhat unconfident" or "neither confident nor unconfident" to discuss pharmacogenomics subjects with another health care provider or patient. At the end of the course, students reported a higher level of confidence regarding different topics in pharmacogenomics, as well as the role of the pharmacist in this area, with $91 \%$ saying they were confident or somewhat confident $(p<.001)$. This analysis was performed comparing numbers of students who were unconfident, somewhat unconfident or did not know prior to the course with numbers of confident and somewhat confident after the course.

Lastly, to determine how much information learned during the P1 year was retained in future courses, an unannounced survey on basic concepts of pharmacogenomics was given to the class when they moved to the second year of the program. Sixty-five out of the 76 students answered the survey. Table 4 provides the questions asked and percentage of questions answered correctly. Most of the students (77\% to $100 \%)$ answered all the questions correctly.

Moreover, graded pharmacogenomics questions were also asked during the examinations in different P2 SBT courses, namely in SBT pulmonology and cardiology modules. These questions were more complex and included therapeutic aspects not covered during the firstyear course. Nine out of the 10 questions were answered correctly by $87 \%$ to $100 \%$ of the class of 76 students, while the remaining question was only answered correctly by $38 \%$ of the class (not shown).

\section{DISCUSSION}

The World Health Organization (WHO) declared that "health care providers, including pharmacists, should be better prepared for clinical decision making by having adequate knowledge about the medicines for which the patient should be tested." "Pharmacists are being recognized and acknowledged as leaders in pharmacogenomics. ${ }^{17}$ 


\section{American Journal of Pharmaceutical Education 2018; 82 (8) Article 6345.}

A

Student self

perception about

the topic

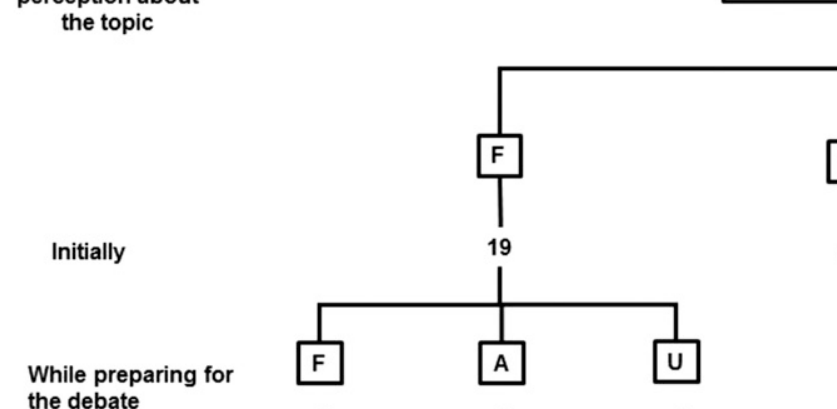

the debate

0

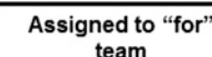

team
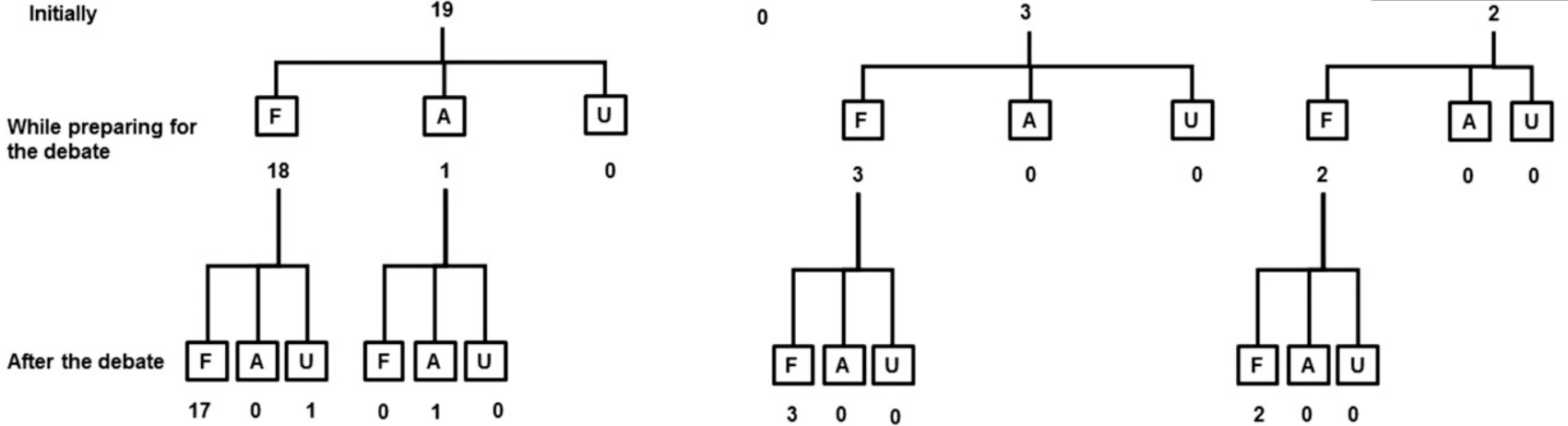

"did not know what

personalized

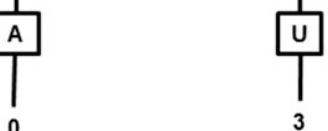

medicine was"

0

0

0

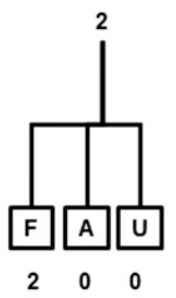

B

Student self

perception about

the topic

Initially

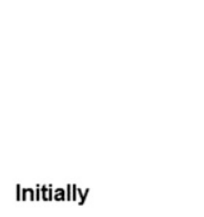

While preparing for the debate
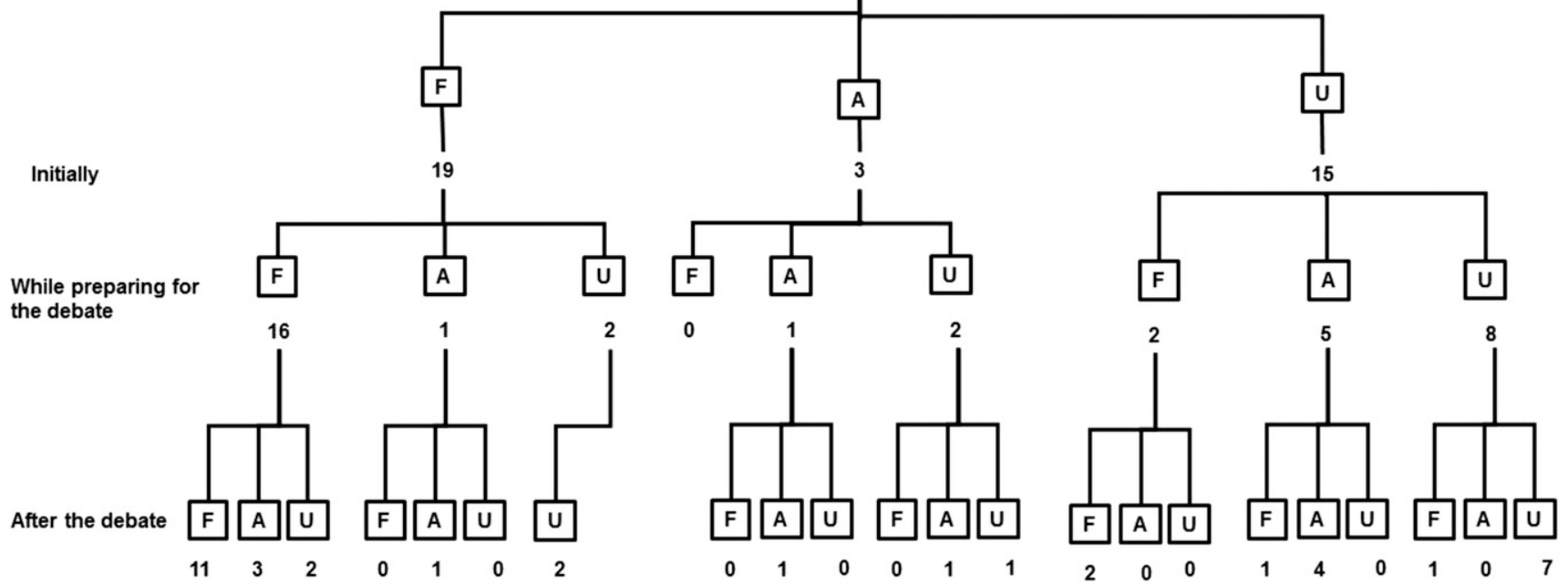

Figure 1. Students' Perceptions about Personalized Medicine and Genetic Sequencing from Team Activity 4 and Change of Thinking. Students who were randomly assigned to "for" (1A) and "against" (1B) personalized medicine were asked for their perception before, during and after the debate. Numbers describe the number of students who were "for" (F), "against" (A), or "undecided" (U).

Currently, a growing number of pharmacy students understands the significance of pharmacogenomics for their future practice. Lee and colleagues surveyed 2,500 pharmacy students and found that $65 \%$ of students acknowledge the importance of pharmacogenomics. ${ }^{18}$ Moen and Lamba reported that $90 \%$ of pharmacy students at the University of Minnesota recognized the importance of pharmacogenomics in improving patients care. ${ }^{19}$

This data contrast studies in which physicians and other health care providers have expressed a lack of confidence or awareness in discussing pharmacogenomic information, testing or educating patients. ${ }^{20,21}$ Some studies report that between $10 \%$ and $13 \%$ of physicians who participated in the study felt confident with their knowledge. ${ }^{20,22}$ There is evidence that supports a deep commitment made by pharmacy educators to provide pharmacogenomics education among all health sciences disciplines. Pharmacists are expected to advise clinicians on matters related to implementation of pharmacogenomics in patient care, ${ }^{23}$ and to ensure the use of pharmacogenomics testing when appropriate for medication therapy. ${ }^{8}$ Furthermore, some pharmacists are also involved in developing prescribing guidelines such as those 
American Journal of Pharmaceutical Education 2018; 82 (8) Article 6345.

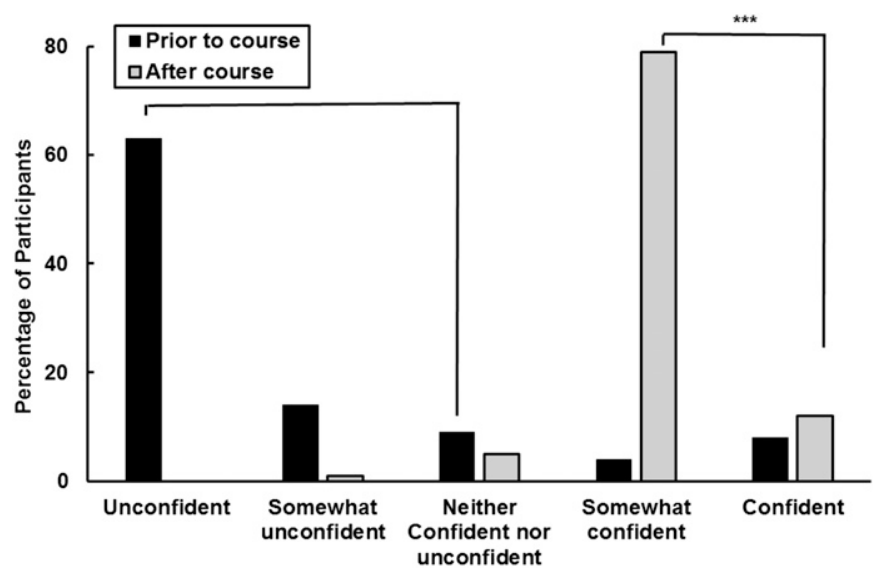

Figure 2. Student Self-Ratings of Overall Confidence and Ability to Discuss Pharmacogenomics with Patients and Health Care Providers. The questions asked were: what was your confidence level about talking and discussing pharmacogenomics aspects with another health care provider or a patient prior the course? and what is your confidence level now after the course?

$(* * * p<.001$, Chi-square analysis, comparing unconfident, somewhat unconfident and did not know prior to the course with confident and somewhat confident after the course)

from the Clinical Pharmacogenetics Implementation Consortium (CPIC), ${ }^{15}$ as well as in the application of pharmacogenomics principles in practice. ${ }^{24}$ But this is an ongoing effort because there are still pharmacists who have expressed their lack of confidence in this matter. $8,23,25,26$

Pharmacogenomic education in PharmD programs has grown rapidly. In 2005, only 32 out of 41 (78\%) pharmacy schools that answered a survey described that they have some components of pharmacogenomics in their curriculum. ${ }^{27}$ In 2010, that number grew to 69 out of 75 $(92 \%) .{ }^{28}$ However, $40 \%$ of these schools offer 10 or fewer didactic hours in pharmacogenomics, ${ }^{28}$ and in some situations, pharmacogenomics is offered only as an elective.

This course is taught during the P1 spring semester, as part of a four-credit course called Biopharmaceutics and Pharmacogenomics. Although there are some challenges in offering the course at an early stage of the education of pharmacy students, such as limited knowledge about pharmacology, the instructor adapted the clinical scenarios to only include drugs that were mentioned previously in other courses to facilitate the discussions. There are also some perceived advantages in offering the course during the first year: students have recently learned about biopharmaceutics, pharmacokinetics, biotechnology, and biochemical pharmacology, and they could apply those concepts without difficulty into the pharmacogenomics section of the course. New pharmacogenomics learning and retention is incorporated and reinforced in the integrative curriculum further in the second and third year, in the System Based Therapeutic (SBT) courses. The pharmacogenomics learning in these SBT courses involves the discussion of particular scenarios, applying and reinforcing the learned concepts as suggested by previous work. ${ }^{29}$ Furthermore, this P1 course includes ethical, legal, social and economic implications, as well as metabolomics, epigenetics and bioinformatics, covering some of the suggested additional pharmacist competencies $^{27,28}$ that were reported as "deficient" in some schools in the 2010 study. $^{28}$

Table 4. Measurement of Retention of Basic Pharmacogenomics Information 6 Months After P1 Pharmacogenomics Course $(\mathrm{N}=65$ out of 76 students enrolled as $\mathrm{P} 2)$

\begin{tabular}{|c|c|c|c|}
\hline & Correct N (\%) & Incorrect N (\%) & Did not Answer \\
\hline $\begin{array}{l}\text { If a patient is an ultra-rapid metabolizer for a specific enzyme, } \\
\text { a medication metabolized by that enzyme will }\end{array}$ & $65(100)$ & 0 & 0 \\
\hline $\begin{array}{l}\text { If a patient is a poor metabolizer for a specific enzyme, } \\
\text { a medication metabolized by that enzyme will }\end{array}$ & $65(100)$ & 0 & 0 \\
\hline $\begin{array}{l}\text { If a patient is an ultra-rapid metabolizer for a specific enzyme, } \\
\text { the patient is at risk of } \\
\text { metabolized by that enzyme. }\end{array}$ & $57(89)$ & $7(11)$ & 1 \\
\hline In which type of patient will a pro-drug have risks of toxicity? & $50(77)$ & $15(23)$ & 0 \\
\hline
\end{tabular}




\section{American Journal of Pharmaceutical Education 2018; 82 (8) Article 6345.}

Pharmacy schools are incorporating various educational approaches and strategies to teach pharmacogenomics. Weitzel and colleagues listed the different factors that affect educational approaches, such as class size and type of curriculum. ${ }^{30}$ Educational approaches include didactic lectures, ${ }^{31}$ clinical exercises and online resources, ${ }^{32}$ personal genomic sequencing, ${ }^{33}$ laboratory exercises ${ }^{34}$ and bionformatics, ${ }^{35}$ flipping content, ${ }^{36}$ shortanswer problem solving, ${ }^{31}$ medical literature review, ${ }^{31}$ experiential activities, ${ }^{37}$ and medical evidence review, among others. Some pharmacy schools have tried implementing students' personal genetic sequencing, ${ }^{33}$ but this approach could be controversial, ${ }^{38}$ and risks failing the four pillars of genetic counseling (autonomy, confidentiality, beneficence, and justice). ${ }^{39}$

In this study, students were exposed to different topics such as patient stratification based on genetic background and involving predicting responders and non-responders, or those with higher or lower risks of developing an adverse effect, discussion of ethical issues and barriers to implementation of genetic testing such as electronic health record or GINA. ${ }^{8,17,30}$ Group activities were offered in addition to lectures. All group activities were well received by the students, and were found useful for their learning.

Some of the concerns expressed by students against personalized medicine are not unusual and have already been expressed by a group of licensed pharmacists in Canada. ${ }^{40}$ Additional studies with medical students in the US and in the UK indicate that they also share the same concerns. ${ }^{41}$

Students who participated in this study reported an increased level of confidence with respect to their knowledge base. As mentioned in the introduction, previous studies have shown that pharmacists were not aware of the pharmacogenomics information in FDA labeling, ${ }^{40}$ which was one of the reasons for incorporating a team activity involving FDA and CPIC recommendations ${ }^{42}$ as part of the course design.

A potential limitation of these assessment methods could be offering the retrospective pre- and post-survey simultaneously at the end of the course. Although the students could retrospectively reflect on their level of knowledge, their answer could have been different if the question was asked directly at the beginning of the course. However, the advantage of the approach used in this study was that student confidentiality was maintained, and, at the same time, to match retrospective pre- and postanswers for each student. Another limitation of this study could be associated with the lack of student response to retention questions, since they were not linked to a grade.

The ultimate goal when designing this course was not only to better prepare pharmacy students to explain and interpret test results, but also to prepare them to help patients, explain the meaning of specific genetic backgrounds, and educate them in the area of pharmacogenetics, as previously reported and suggested. ${ }^{43}$

\section{CONCLUSION}

The implementation of a new course of Pharmacogenomics with a series of active learning activities (genetic disease, CPIC/pharmacogenomics guideline, genetic counseling, and a debate) was effective. Students found these activities useful, and reported an increased level of confidence, awareness and knowledge to address pharmacogenomics cases with patients or with other healthcare providers.

\section{ACKNOWLEDGMENTS}

The authors thank Dr. Angela Obringer, WVU genetic counselor, for facilitating one of the active learning experiences; WVCTSI Biostatistics Core; Drs. Patrick Callery, Mary Stamatakis and Marie Abate at WVU for their feedback and support; and Dr. Melissa Medina for her guidance during IRB process. The project described was supported by the National Institute of General Medical Sciences, U54GM104942. The content is solely the responsibility of the authors and does not necessarily represent the official views of the NIH.

\section{REFERENCES}

1. Vesell ES. Pharmacogenetics. N Engl J Med. 1972;287(18): 904-909.

2. Accreditation Council for Pharmacy Education. Accreditation Standards and Key Elements for the Professional Program in Pharmacy Leading to the Doctor of Pharmacy Degree. ACPE. 2015:39.

3. Feero WG, Kuo GM, Jenkins JF, Rackover MA. Pharmacist education in the era of genomic medicine. J Am Pharm Assoc. 2012;52(5):e113-e121.

4. Mclnerney JD. Core Competencies in Genetics for Health Professionals. Natl Coalit Heal Prof Educ Genet. 2007;

(September):1-9.

5. Gurwitz D, Lunshof JE, Dedoussis G, et al. Pharmacogenomics education: International Society of Pharmacogenomics recommendations for medical, pharmaceutical, and health schools deans of education. Pharmacogenomics J. 2005;5(4):221-225. 6. Accreditation Council for Pharmacy Education. Accreditation Standards and Key Elements for the Professional Program in Pharmacy Leading to the Doctor of Pharmacy Degree. ACPE. 2015:39.

7. American College of Clinical Pharmacy. A vision of pharmacy's future roles, responsibilities, and manpower needs in the United States. Pharmacotherapy. 2000;20(8):991-1020.

8. Haidar CE, Hoffman JM, Johnson SG. ASHP statement on the pharmacist's role in clinical pharmacogenomics. Am J Heal Pharm. 2015;72(7):579-581. doi:10.2146/sp150003.

9. Formea CM, Nicholson WT, McCullough KB, et al. Development and evaluation of a pharmacogenomics educational program for pharmacists. Am J Pharm Educ. 2013;77(1):10. 


\section{American Journal of Pharmaceutical Education 2018; 82 (8) Article 6345.}

10. Calzone KA, Jerome-D'Emilia B, Jenkins J, et al. Establishment of the genetic/genomic competency center for education. $J$ Nurs Scholarsh an Off Publ Sigma Theta Tau Int Honor Soc Nurs. 2011; 43(4):351-358.

11. Harirforoosh S, Fleckenstein L, Mahajan P, Aruoma OI, Huang Y, Moridani M. The importance of including topics related to pharmacogenetics, pharmacogenomics, and medical genetics in the pharmacy curriculum. Am J Pharm Educ. 2009;73(6):114.

12. Wade N. A Decade Later, Genetic Map Yields Few New Cures. The New York Times. 2010:June 13th, A1.

13. McKinnon R, Anderson C. Transforming pharmaceutical education to accelerate the acceptance and implementation of personalized medicine. Am J Pharm Educ. 2011;75(6):107.

14. Salari K. The dawning era of personalized medicine exposes a gap in medical education. PLoS Med. 2009;6(8).

15. Daly AK. Is there a need to teach pharmacogenetics? Clin Pharmacol Ther. 2014;95(3):245-247.

16. Zee SJHVA-HM der. Background Paper 7.4: Pharmacogenetics and Stratified Medicine.; 2013.

17. Johnson JA. Pharmacists should jump onto the clinical pharmacogenetics train. Am J Heal Pharm. 2016;73(23):2013-2016. 18. Lee KC, Hudmon KS, Ma JD, Kuo GM. Evaluation of a shared pharmacogenomics curriculum for pharmacy students. Pharmacogenomics. 2015;16(4):315-322.

19. Moen M, Lamba J. Assessment of healthcare students' views on pharmacogenomics at the University of Minnesota.

Pharmacogenomics. 2012;13(13):1537-1545.

20. Haga S, Burke W, Ginsburg G, Mills R, Agans R. Primary care physicians' knowledge of and experience with pharmacogenetic testing. Clin Genet. 2012;82(4):388-394.

21. Passamani E. Educational challenges in implementing genomic medicine. Clin Pharmacol Ther. 2013;94(2):192-195.

22. Stanek EJ, Sanders CL, Taber K a J, et al. Adoption of pharmacogenomic testing by US physicians: results of a nationwide survey. Clin Pharmacol Ther. 2012;91(3):450-458.

23. Mccullough KB, Formea CM, Berg KD, et al. Assessment of the pharmacogenomics educational needs of pharmacists. Am J Pharm Educ. 2011;75(3).

24. Owen JA, Director S, Prac-tice P. Integrating pharmacogenomics into pharmacy practice via medication therapy management American Pharmacists Association. J Am Pharm Assoc. 2011; 51(6):64-74.

25. Tuteja S, Haynes K, Zayac C, Sprague JE, Bernhardt B, Pyeritz R. Community pharmacists' attitudes towards clinical utility and ethical implications of pharmacogenetic testing. Per Med. 2013;10(8):793-800

26. Johnson JA, Bootman JL, Evans WE, et al. Pharmacogenomics: A Scientific Revolution in Pharmaceutical Sciences and Pharmacy

Practice. Report of the 2001-2002 Academic Affairs Committee. Am $J$ Pharm Educ. 2002;66(4):12S-15S.
27. Latif DA, McKay AB. Pharmacogenetics and pharmacogenomics insturction in colleges and schools of pharmacy in the United States. Am J Pharm Educ. 2005;69(2):Article 23.

28. Murphy JE, Green JS, Adams LA, Squire RB, Kuo GM, Mckay A. Pharmacogenomics in the curricula of colleges and schools of pharmacy in the United States. Am J Pharm Educ. 2010;74(1):7. 29. Vaksman N, Barnett M, Hakobyan L, Kucher I, Louie Dr. MC. The impact of incorporating of pharmacogenomics into the pharmacy curriculum on student interest. Pharm Educ. 2012;12(1):31-36.

30. Weitzel KW, Aquilante CL, Johnson S, Kisor DF, Empey PE. Educational strategies to enable expansion of pharmacogenomicsbased care. Am J Heal Pharm. 2016;73(23):1986-1998.

31. Brazeau DA, Brazeau GA. A required course in human genomics, pharmacogenomics, and bioinformatics. Am J Pharm Educ. 2006;70(6).

32. Farrell CL, Goodbar NH, Buckhaults P, et al. Clinical application of pharmacogenomics through clinical exercises and online resources. Curr Pharm Teach Learn. 2014;6(4):571-576.

33. Adams SM, Anderson KB, Coons JC, et al. Advancing pharmacogenomics education in the core pharmd curriculum through student personal genomic testing. Am J Pharm Educ. 2016;80(1). 34. Farrell CL, Pedigo NG, Messersmith AR. Application of genomic principles to pharmacotherapy of cancer. Am J Pharm Educ. 2014;78(3).

35. Springer JA, Iannotti N V., Kane MD, Haynes K, Sprague JE. Pharmacogenomics training using an instructional software system. Am J Pharm Educ. 2011;75(2):32.

36. Nickola TJ, Munson AM. Pharmacogenomics Primer Course for First Professional Year Pharmacy Students. Pharmacogenomics J. 2014;15(1):39-48.

37. Drozda K, Labinov Y, Jiang R, et al. A pharmacogenetics service experience for pharmacy students, residents, and fellows. Am J Pharm Educ. 2013;77(8):175.

38. Taylor ATS, Rogers JC. The ethical implications of genetic testing in the classroom. Biochem Mol Biol Educ. 2011;39(4):253-260.

39. Baumiller RC, Cunningham G, Fisher N, et al. Code of ethical principles for genetics professionals: an explication. Am J Med Genet. 1996;65(3):179-183.

40. de Denus S, Letarte N, Hurlimann T, et al. An evaluation of pharmacists' expectations towards pharmacogenomics.

Pharmacogenomics. 2013;14(2):165-175.

41. Haga SB, O’Daniel JM, Tindall GM, Lipkus IR, Agans R. Survey of US public attitudes toward pharmacogenetic testing. Pharmacogenomics J. 2012;12(3):197-204.

42. Weinshilboum R, Wang L. Pharmacogenomics: Bench to bedside. Discov Med. 2005;5(25):30-36.

43. Fargher EA, Eddy C, Newman W, et al. Patients' and healthcare professionals' views on pharmacogenetic testing and its future delivery in the NHS. Pharmacogenomics. 2007;8(11):1511-1519. 